Maple Protocol for End of Life Care. 2019 Apr 25[cited 2020 Aug 9]. Available from:http://vishnudutas.com/wp-content/uploads/2020/03/ Blue-Maple-1-End-of-Life-Care-Policy-Document-of-ManipalHospitals-1.pdf

13. All India Institute of Medical Sciences (AIIMS), New Delhi. Guidelines for End of Life Care, AllMS, New Delhi. 2020 [cited 2020 Aug 9]. Available from: https://www.palliativecare.in/wp-content/uploads/2020/06/ AlIMS-EOLC-Policy-2020.pdf

14. Australian Resuscitation Council, New Zealand Resuscitation Council. Section 10: Guideline 10.5. Legal and Ethical Issues related to Resuscitation. 2015 Nov[cited 2020 Aug 9]. Available from: https:// resus.org.au/download/section_10/guideline-10-5-nov-2015.pdf

\title{
Centring patient autonomy in DNAR decisions
}

\section{OLINDA TIMMS, SUNIL K PANDYA, AMAR JESANI, SANDHYA SRINIVASAN}

\section{Keywords: DNAR, resuscitation, CPR, guidelines, ICMR}

The Response from the ICMR team of Dr Mani et al (1) to the IJME Editorial (2) on the ICMR DNAR Guidelines (3) provides some answers to the gaps and questions raised, and it is hoped that these will find a place in revised versions of the document. The document Disclaimer said "further revisions" were planned, based on perceptions and experiences of clinicians and the public; an early revision will allow for better acceptance of the Guidelines.

The word "consensus" in the title of the Guidelines conveys the impression that there were wide ranging consultations, but this was not the case. A guideline that applies to all doctors, and can potentially impact every patient, deserves much wider discussion. Such discussion should take place with clinical societies, doctors' associations, the National Medical Commission, as it is the apical body governing medical practice, and health activist groups. Discussions with patients' groups, women's, dalits' and other underprivileged and discriminated groups are needed to address their concerns about the misuse of the provisions. The ICMR "Bioethics page" may not have been the best location of the call for a broad consultation, as clinicians and non-researchers hardly ever visit the page. Valuable contextual feedback could surely have emerged from circulation to clinical and patient groups.

The Guidelines appear to be scripted from a medical perspective, with process flow and signature sheets that view ethical responsibility through a paternalist lens, describing

Authors: Olinda Timms (olindatimms@gmail.com), Division of Health and Humanities, St Johns Research Institute, Bengaluru 560034 INDIA; Sunil K Pandya (shunil3@gmail.com), Department of Neurosurgery, Jaslok Hospital and Research Centre, Dr GV Deshmukh Marg, Mumbai 400026 INDIA; Amar Jesani (amar.jesani@gmail.com) Independent Consultant, Researcher and Teacher in Bioethics and Public Health, Swatantrya Sainik Nagar, Andheri West, Mumbai 400058 INDIA; Sandhya Srinivasan (sandhya199@gmail. com), Independent Journalist, 8, Sea Doll, Chimbai, Bandra West, Mumbai 400 050, INDIA

To cite: Timms O, Pandya SK, Jesani A, Srinivasan S. Centring patient autonomy in DNAR decisions. Indian J Med Ethics. 2020 Oct-Dec; 5(4) NS: 3401.DOI: $10.20529 /$ IJME.2020.096.

Published online first on September 11,2020.

(c) Indian Journal of Medical Ethics 2020 clinician's steps in decision-making and the requirement for consent. In fact the DNAR option is one that is exercised by the patient (or surrogate) after full understanding of the precarious condition and futility of medical efforts, and this option is then executed through a DNAR order written by the doctor. The DNAR decision needs to be centred on the patient and ethically supported by the physician; this aspect was inadequately described in the Guidelines.

Though not provided by these Guidelines, express legal sanction for DNAR orders consented to by patient or surrogate would be crucial to effective implementation of this guideline. ICMR lacks the legal standing to enforce these Guidelines, prescribe punitive measures or arbitrate, as it does not govern medical practice.

Since DNAR refers to CPR only, there is a need to distinguish, right at the start of the Guidelines, between CPR and any other drug or fluid therapy that may have a resuscitating effect.

The response says that "treating doctor" and "physician-incharge" implies Head of Unit or "senior doctor" but this would have to be made clear. This end-of-life decision by the patient and doctor is important enough to warrant responsible ownership of the process by a senior doctor who would be experienced and accountable.

While the Response acknowledges the role of Hospital Ethics Committees, this it is unfortunately not mentioned in any part of the document, FAQs, or Algorithm chart.

The revised document should also include the important clarification in the Response about sharing DNAR orders with the medical team and nurses, during handing over between shifts.

Since the Response has urged clinicians not to use the term "vegetative" in speaking to surrogates, the word should be removed from the "Surrogate Information Sheet" in the document.

The process described in the document does not give sufficient time for the patient and family to study the implications of DNAR. According to the answer to Q 2 (Annexure 3), the form would be issued when the patient was already in a terminal state. Most internationally reputed hospitals issue the form at the time of admission so that 
patient and family have adequate opportunity to study its implications. The preamble to the form specifies the condition under which it would be necessary to use it. Providing an opportunity to study it well in advance enables patient and family to discuss the implications of DNAR at times that are relatively free from stress, as against discussing it when the patient has passed into a terminally ill state. This step would make Q 4 unnecessary and would promote the discussion referred to in Q 13.

As expressed in the Editorial (2), this guidance document can promote patient autonomy at end of life and support clinical decisions, as it provides care standards, care pathways and documentation in a grey area of practice.

\section{References}

1. Mani RK, Simha S, Gursahani R, Mehta D, Garg P, Mathur R. DNAR Guidelines from ICMR:Meeting a felt need.Indian JMed Ethics. Published online first on September 10, 2020. Doi:10.20529/IJME.2020.095.

2. Timms O. DNAR Guidelines: Supporting end of life care. Indian J Med Ethics. 2020 Jul-Sep; 5(3) NS:180-1. Doi: https://doi.org/10.20529/ IJME.2020.081.

3. Mathur R.ICMR Consensus Guidelines on 'Do Not Attempt Resuscitation'. Indian J Med Res. 2020 Apr [cited 2020 Sep 5]; 151(4):303-10. Available from:http://www.ijmr.org.in/text.asp?2020/151/4/303/284215

\section{Be a part of IJME}

IJME invites readers to submit research studies, comments, case studies, reports, reviews, letters, as also poems, short stories, original paintings and photographs of print quality ( both in colour and $\mathrm{B} / \mathrm{W}$ ) to be considered for publication.

All submitted matter is subject to peer review.

Contributors are neither paid nor charged any fee for published matter. 